\title{
UCRL-TR-206760
}

LAWRENCE LIVERMORE N A T IO N A L LABORATORY
Modeling Production Plant
Forming Processes

Moon Rhee, Richard Becker, Richard Couch, Ming Li, Ming Li

September 23, 2004 
This document was prepared as an account of work sponsored by an agency of the United States Government. Neither the United States Government nor the University of California nor any of their employees, makes any warranty, express or implied, or assumes any legal liability or responsibility for the accuracy, completeness, or usefulness of any information, apparatus, product, or process disclosed, or represents that its use would not infringe privately owned rights. Reference herein to any specific commercial product, process, or service by trade name, trademark, manufacturer, or otherwise, does not necessarily constitute or imply its endorsement, recommendation, or favoring by the United States Government or the University of California. The views and opinions of authors expressed herein do not necessarily state or reflect those of the United States Government or the University of California, and shall not be used for advertising or product endorsement purposes.

This work was performed under the auspices of the U.S. Department of Energy by University of California, Lawrence Livermore National Laboratory under Contract W-7405-Eng-48. 


\title{
MODELING PRODUCTION PLANT FORMING PROCESSES
}

\author{
Tech Base Project \\ (July - Sept 2004)
}

Final Report

Submission Date: September 10, 2004

by

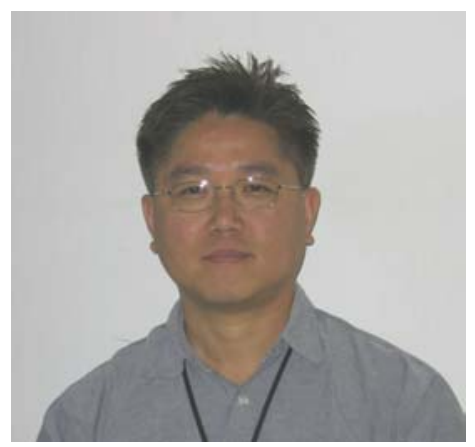

Moon Rhee (PI)

Richard Becker

Richard Couch

New Technologies Engineering Division

Lawrence Livermore National Laboratory

Phone: (925) 424-4990

Email: rhee1@1lnl.gov

Prepared for

Center for Computational Engineering 


\section{Project Overview}

Engineering has simulation tools and experience in modeling forming processes. Y-12 personnel have expressed interest in validating our tools and experience against their manufacturing process activities such as rolling, casting, and forging etc. We have demonstrated numerical capabilities in a collaborative DOE/OIT project with ALCOA that is nearing successful completion. The goal was to use ALE3D to model Alcoa's slab rolling process in order to demonstrate a computational tool that would allow Alcoa to define a rolling schedule that would minimize the probability of ingot fracture, thus reducing waste and energy consumption. It is intended to lead to long-term collaboration with Y-12 and perhaps involvement with other components of the weapons production complex. Using simulations to aid in design of forming processes can: decrease time to production; reduce forming trials and associated expenses; and guide development of products with greater uniformity and less scrap.

\section{Project Goals}

The immediate objective of the proposed work is to employ our numerical capabilities for rolling process validations and foster a close collaboration with Y-12. The effort would be to attempt to validate our ability to model rolling experiments and assess our ability to address other forming processes at $\mathrm{Y}-12$. The intention is to grow this interaction into a longer-term relationship which would receive ADAPT Program support. The experience gained here would translate to other Engineering projects.

\section{Relevance to Lab Mission}

Modeling forming processes and material response is a significant responsibility of the Engineering Directorate. This effort will contribute to Engineering's core competency in numerical modeling and material response. The capability demonstrated in this project would be supportive of other forming projects where geometric fidelity and control of material properties are critical. A successful effort will also contribute programmatically to DNT objectives.

\section{FY04 Accomplishments and Results}

The current project was initiated at the end of July 2004. An initial visit of LLNL personnel to Y-12 occurred on week of September 15-16, 2004. The purposes of the visit were:

- to familiarize ourselves with the suite of Y-12 forming issues (see, for example, Figure 1 for rolling simulation and Figure 2 for casting simulation), including advanced concepts, and identify areas where improved modeling might provide a significant benefit. 
- to assess existing material properties data and identify approaches for filling gaps in knowledge.

The technical interchange at Y-12 was successful yielding:

- Information relevant to Y-12 modeling and forming processes.

- An agreement to collaborate on FY05 tech base activities.

- A path forward to produce a joint ADAPT proposal focused on understanding deformation forming processes.

Also, the following subtasks have been performed:

- Preliminary survey of high temperature material properties for use in simulations.

- Began a series of calculations to evaluate ALE3D capability to model casting. An example of casting simulation is given in Figure 2.

An ADAPT proposal will be produced by the end of FY04. The exit plan of this project is transition to an ADAPT funded project in FY06.

\section{FY05 Proposed Work}

We will collaborate with Y-12 personnel to determine a rolling event and other forming data that can be used as validation data for our codes and techniques. We will attempt to predict microstructural evolution as well as geometric data. Knowledge of material properties relevant to forming regimes will be exchanged. We will also familiarize ourselves with other forming activities at Y-12 and use this information in constructing an ADAPT proposal to initiate with FY06 funding. Rolling validation calculations will be performed against rolling data from Y-12. The proposed work will be completed by 9/30/05.

For FY05 Tech Base activities we are considering a proposal that would address:

- Rolling validation calculations will be completed by 9/30/05.

- Validation of ALE3D for reproducing rolling data

- geometric fidelity

$\circ$ evolution of microstructure

- Familiarize ourselves with the suite of Y-12 forming issues, including advanced concepts, and identify areas where improved modeling might provide a significant benefit.

- Perform code validation calculations where appropriate. An example would be evaluating casting modeling codes against $\mathrm{Y}-12$ specific data. 


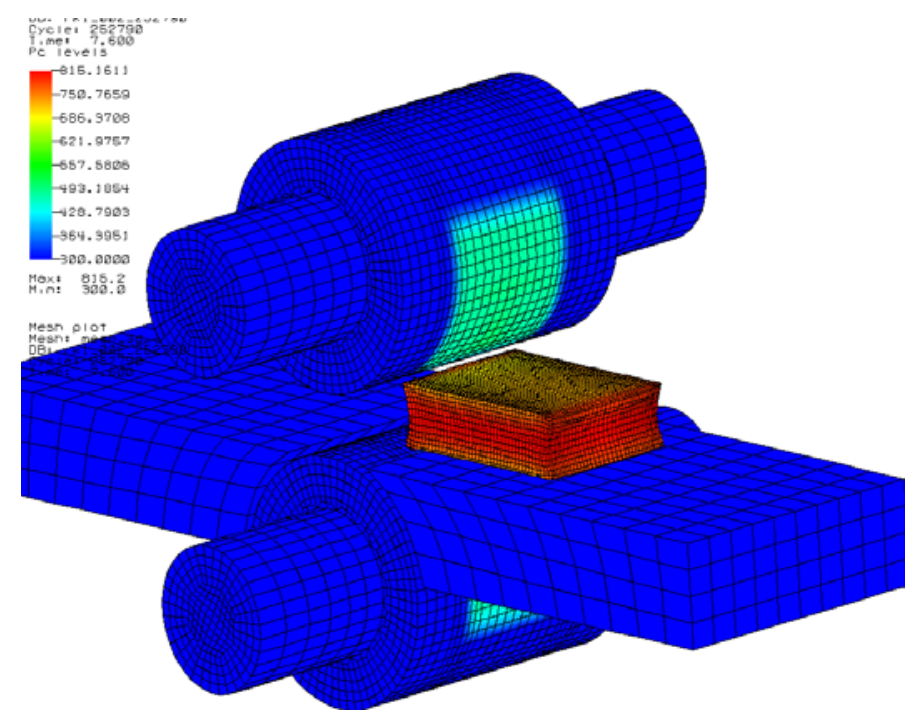

Figure 1. A finite element model representing rolls, slab and supports is illustrated. Thermal contours are shown.

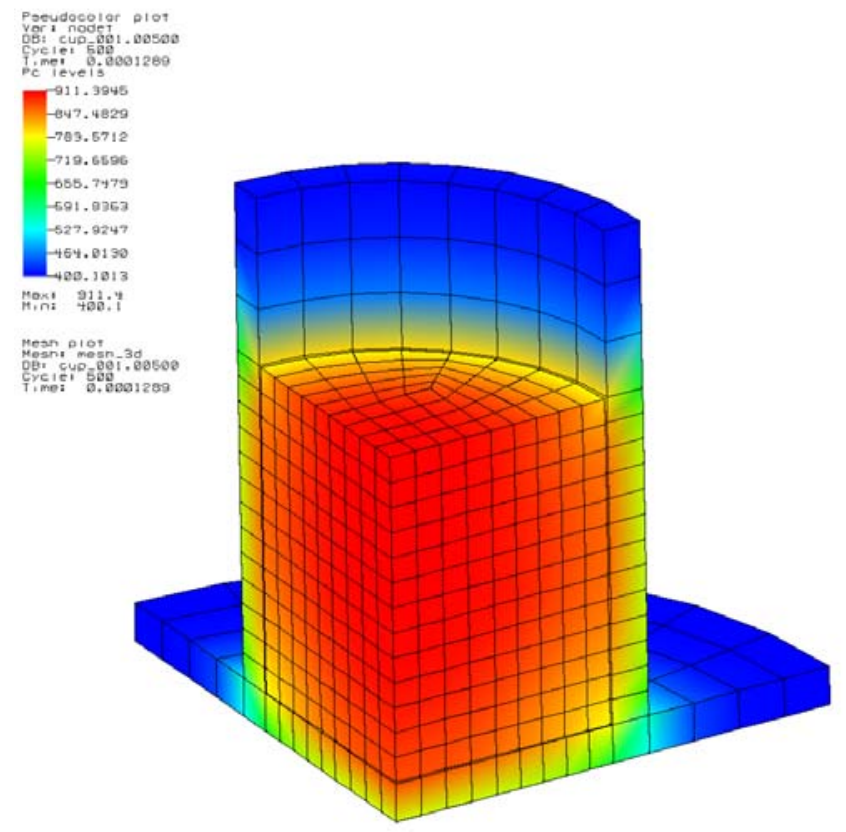

Figure 2. Illustration of a casting simulation showing thermal contours. 